\section{Control of substrates on pothole geometry}

\author{
Balai Chandra Das* \\ Department of Geography, Krishnagar Govt. College, Krishnagar, \\ Nadia 741 101, India
}

In the present study, we recorded the depth $(d)$, aperture radius $(r)$, chamber radius $\left(r_{c}\right)$ and size of the largest grinding tool $(G)$ of 64 potholes from Subarnarekha river bed near Ghatsila, Jharkhand, India. Subsequent to the analysis, distinct control of substrates on pothole morphology became apparent. The average $d / r$ ratio $(\gamma) \mathbf{2 . 0 7}$, of potholes on quartzite was significantly different from that of potholes on mica-schist. Variations of major and minor aperture radii of micaschist $(60.59 \%)$ were much higher than those on quartzite $(18.66 \%)$. The $d-r$ linear law, $d=N r+M$ (where $M=$ critical size of seminal depression that grows into a mature pothole and $N=$ ratio between the rate of deepening and widening) seemed to hold good for potholes in both the substrates. Thirty four potholes on quartzite exhibited $M=20 \mathrm{~cm}, N=1.2$ explaining the faster rate of deepening than widening. Thirty potholes on mica-schist exhibited $M=4.9 \mathrm{~cm}, N=0.67$ explaining the faster rate of widening. On quartzite, potholes with $d / r>2$ exhibited $r_{c}>r$ which was absent in potholes on mica-schist. The $d-G$ and $r-G$ relations found in potholes on quartzite were insignificant for those on mica-schist.

Keywords: Aperture of potholes, chamber of potholes, depth/radius ratio, largest grinding tool.

PoTHOLES are a unique feature of bedrock riverbed and considered as key role players in bedrock channel inci$\operatorname{sion}^{1-3}$. Whatever their mode of initiation is, potholes grow by the interaction between riverbed and particles driven in persistent, nontransient vortices ${ }^{4,5}$. Elston ${ }^{6,7}$ classified potholes into abrasive and solution form on the basis of erosion processes that formed them. Alexander ${ }^{8}$ subdivided abrasive potholes on the basis of the angle of entry of water into the potholes. On the basis of shape and morphology, potholes were classified as undercut potholes 9 , potholes with central boss ${ }^{10-13}$, potholes with entry furrows ${ }^{14}$, potholes with exit furrows ${ }^{15,16}$ and compound potholes ${ }^{2,17}$. But the recent trend is to model process-form interaction between pothole morphology and hydraulics within it. Potholes grow as a result of combined erosion of walls and floors. Efficacy of erosion phenomena ${ }^{4,5}$ determines the differences in the erosion rate of wall and floor of the potholes. Springer et al. ${ }^{4,5}$ established a power relationship between average radius $(r)$ and depth $(d)$ of the pothole and expressed the relation

\footnotetext{
*e-mail: balaidaskgc@rediffmail.com
}

as $r \propto d^{\varepsilon}$. They represented potholes as radially expanding cylinders and designed growth model on geometrical base. They also found that the rate of deepening was faster than the widening of pothole aperture. Using data from previous studies and latest data from the Smith river, Oregon, USA, Pelletier et $a .^{18}$ concluded that potholes in bedrock channels commonly evolved to an optimal depth to radius ratio $(d / r=\gamma)$ of 2 , as bottom shear stress maximizes at $\gamma=1$. Size of the largest grinding tool $(G)$ was reported to be equal to the radius $(r)$ and proportional to the depth $(d)$ of pothole within which it was stored. Abbott and Pottratz ${ }^{19}$ documented $\gamma$ of 140 potholes ranging from 1 to 2 . They reported a higher value of $\gamma$ in basalt rock and lower value in calcareous rock. Therefore, type and nature of the substrate have significant control on pothole geometry along with grinding tools ${ }^{4,5}$, channel slope, flow depth ${ }^{17}$ and local streambed topography. Sengupta and Kale ${ }^{20}$ found weak correlation between pothole size and rock properties. Yet the role of the substrate on pothole morphometry is less explored. The present paper, based on empirical study, reports the role of substrate type on variation in pothole dynamics.

After originating from Nagri Peak (610 m) of Ranchi hill area, the Subarnarekha river traverses through Ranchi, Seraikela, Kharsawan and East Singhbhum districts in the state of Jharkhand. Thereafter, it flows through Jhargram district in West Bengal for $83 \mathrm{~km}$ and Balasore district of Odisha for $79 \mathrm{~km}$ to join the Bay of Bengal near Talsari (Figure 1). The total length of the river is $395 \mathrm{~km}$. The rain-fed river covers a drainage area of 12,629 sq. $\mathrm{km}$ and its average annual yield is $5943 \mathrm{~m}^{3}$ (ref. 21).

Surface exposure of hard, massive, foliated and gently sloping ultrabasic epidiorite, hornblende/mica-schist and phyllite and quartzite of Singhbhum Group of rocks of Lower Proterozoic eon (Paleoproterozoic era, $2500 \mathrm{Ma}$ to $1700 \mathrm{Ma})$ are recorded around Ghatshila ${ }^{22}$ (Figure 2). Foliations of mica-schist dip $50-70^{\circ}$ towards south and south-east at Moubhandar and south and south-west at Bhatajhor-Subarnarekha confluence. A fault line runs parallel along the right bank of Subarnarekha from northwest to south-east. Nischintapur-Gonala Fault arch (eastnorth-west) runs across the river and joins the former fault $^{22}$. Outcrop of quartzite is aligned east-west across the river atop which cylindrical potholes are sculpted at Bhatajhor-Subarnarekha Confluence. At Moubhandar site, potholes are relatively shallow and broad and engraved atop streambed of mica-schist.

The flow of the river is interposed by a dike-like outcrop of quartzite $\left(22^{\circ} 34^{\prime} 06^{\prime \prime} \mathrm{N}, 88^{\circ} 28^{\prime} 51^{\prime \prime} \mathrm{E}\right)$ aligned at a right angle across the mica-schist river bed of Subarnarekha at Ghatshila, Jharkhand ${ }^{22}$. Atop this quartzite outcrop, a cluster of about 40 potholes is sculpted at Bhatajhor-Subarnarekha confluence (Figure 2). The obstacle of the dike-like outcrop of quartzite made stream 


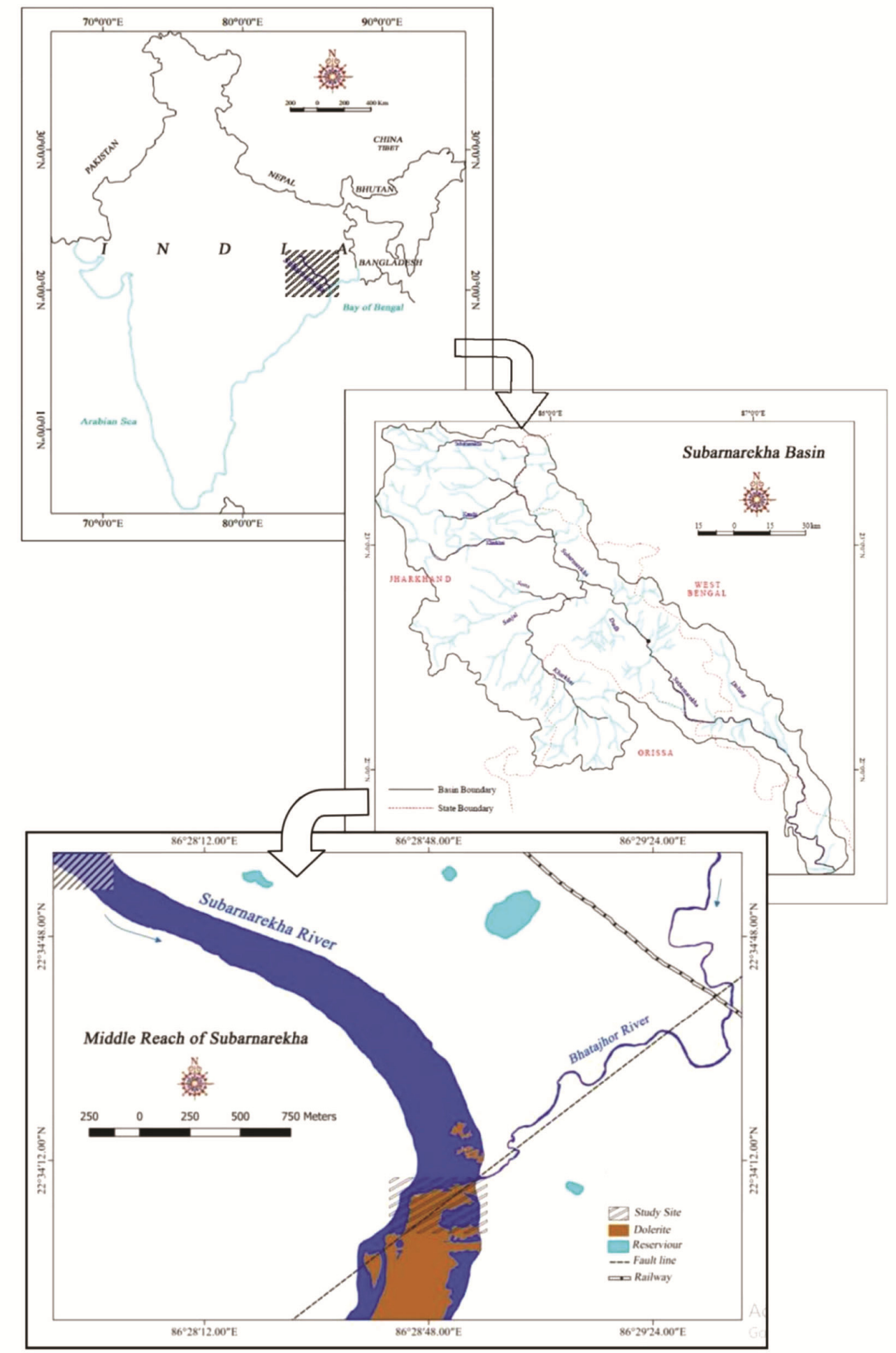

Figure 1. Location of the study area ${ }^{21}$.

flow disruptive, turbulent and many folds powerful than the flow through normal channel and facilitated engraving potholes on vertical joints on quartzite substrate. We recorded the depth $(d)$, radii of aperture $(r)$ and chamber $\left(r_{\mathrm{c}}\right)$ of 34 potholes at this site. Weight and long $(L)$, in- termediate $(I)$ and short $(S)$ axes of the largest grinding tool found in pothole were also recorded.

Another smaller cluster of about 30 potholes on micaschist substrate ${ }^{22}$ was also studied at about $5.5 \mathrm{~km}$ upstream $\left(22^{\circ} 35^{\prime} 39^{\prime \prime} \mathrm{N}, 88^{\circ} 26^{\prime} 45^{\prime \prime} \mathrm{E}\right)$ near Hindustan 
Copper Limited (HCL) plant at Moubhandar. The river bed was characterized by the presence of abrasive, smoothed and polished ${ }^{2,3}$ features like ripples, flutes, furrows, runnels ${ }^{23}$ and potholes. We documented depth $(d)$ and the radius of aperture $(r)$ of 30 potholes at this site. Different parameters of the largest grinding tool were also recorded.

Dimensions of potholes' and dimensions of largest grinding tools were recorded from two different sites (5.5 km apart) in Subarnarekha river bed near Ghatshila. Data on depth $(d)$, radius major $\left(r_{\mathrm{M}}\right)$ and radius minor $\left(r_{\mathrm{m}}\right)$ of apertures of 34 potholes were collected from Bhatajhor-Subarnarekha Confluence site. Lengths of long $(L)$, intermediate $(I)$ and short $(S)$ axes of the largest grinding tool from each of the 34 potholes were also recorded. At Moubhandar site, all the above mentioned parameters of 30 potholes were recorded except chamber radius $\left(r_{\mathrm{c}}\right)$ which was absent there.

Variation in radius $\left(r_{\Delta}\right)$ or degree of difference between radius major $\left(r_{\mathrm{M}}\right)$ and radius minor $\left(r_{\mathrm{m}}\right)$ of aperture was calculated as

$$
r_{\Delta}=\left(\frac{r_{M}-r_{m}}{r}\right) \times 100,
$$

where $r=\left(r_{M}+r_{m}\right) / 2$.

Equality of average depth/radius ratio $(\gamma)$ of potholes of two different substrates was compared with $\gamma=2$, the findings of Pelletier et al. ${ }^{18}$ using $t$-test as ${ }^{24}$

$$
t=\frac{\gamma-2}{\sigma \sqrt{n-1}}
$$

where $\sigma$ is the standard deviation of samples and $n$ is the sample size and null hypothesis $\left(H_{0}\right):$ depth/radius ratio of potholes on quartzite and potholes on mica-schist are not different; $\left(H_{0}: \gamma_{\mathrm{PD}}=\gamma_{\mathrm{PM}}\right)$ was tested using $t$-test as ${ }^{24}$

$$
t=\frac{\gamma_{\mathrm{PD}}-\gamma_{\mathrm{PM}}}{s \sqrt{\frac{1}{n_{\mathrm{PD}}}+\frac{1}{n_{\mathrm{PM}}}}},
$$

where $n_{\mathrm{PD}}$ is the sample size of potholes on quartzite and $n_{\mathrm{PM}}$ is the sample size of potholes on mica-schist and

$$
s=\sqrt{\frac{\left(n_{\mathrm{PD}} \times \sigma_{\mathrm{PD}}^{2}\right)+\left(n_{\mathrm{PM}}-\sigma_{\mathrm{PM}}^{2}\right)}{\left(n_{\mathrm{PD}}+n_{\mathrm{PM}}\right)-2}},
$$

where $\sigma_{\mathrm{PD}}^{2}$ and $\sigma_{\mathrm{PM}}^{2}$ are variances of $\gamma_{\mathrm{PD}}$ and $\gamma_{\mathrm{PM}}$ respectively.

Regression equations (linear and power law) and bi-variate correlations were computed in MS Excel.

The average depth and radius of 34 potholes on quartzite at Bhatajhor-Subarnarekha confluence is $52.65 \mathrm{~cm}$ and $27.36 \mathrm{~cm}$ respectively. The average depth/radius ratio of these potholes on quartzite $\left(\gamma_{\mathrm{PD}}\right)$ substrate is 2.07 which affirms the findings at Sunxi, Lonxi and Gatineau rivers by $\mathrm{Ji}$ et $a .^{25}$, Orange river by Springer et al. ${ }^{4}$, Mino river by Álvarez and Álvarez ${ }^{26}$, Indrayani river by Kale and Shingade ${ }^{27}$, Kurokawa river by Sato et al. $^{28}$ and Wubu river by Ren et al. ${ }^{29}$, where potholes are carved in relatively harder rocks (granite, gneiss, basalt, sandstone). Pelletier et al. ${ }^{18}$ using data of previous scholars and data of their study on Smith River, Oregon, reported that the average depth/radius ratio $(\gamma)$ of most of the potholes is 2.00. Our finding $\gamma_{\mathrm{PD}}=2.07$ confirms with the findings of Pelletier et al. ${ }^{18}$ at $95 \%$ and $99 \%$ confidence level (Table 1). There are $12(35.3 \%)$ potholes in modal class (Figures $3 a$ and $4 a$ ) with a modal value of $\gamma_{\mathrm{PD}}=1.85$.

Higher value of $\gamma_{\mathrm{PD}}$ is explained as: (i) On dike-like outcrop of quartzite, the gliding stream flow was supercritical, extremely gyratory and the stream power was many folds than that of the mica-schist site. Highly jointed local lithology and severely rugged topographycontrolled vertex-velocity carved cylindrical potholes of higher $\gamma_{\mathrm{PD}}$. (ii) $\mathrm{N}$ component $^{25}$ of linear law $(d=$ $N r+M)$, i.e. $d=1.195 r+19.94(N>1)$ and $r=0.27 d+$ $13.12(N<1)$, indicates faster rate of deepening than widening of pothole and higher depth/radius value. This is because of higher stream power and continuous gyratory abrasion by relatively larger grinding stone atop the floor. (iii) The event of suspended-load size grinding tools blown away from the potholes by high vortices' velocity not only reduces the chance of abrasion of walls and thereby widening of aperture, but also relatively increases the rapid deepening by bed-load size grinders ${ }^{30}$.

Figure $5 a$ shows that the pothole depth increases faster than radius ${ }^{4,5,17}$. Therefore the value of $\gamma$ at each of the

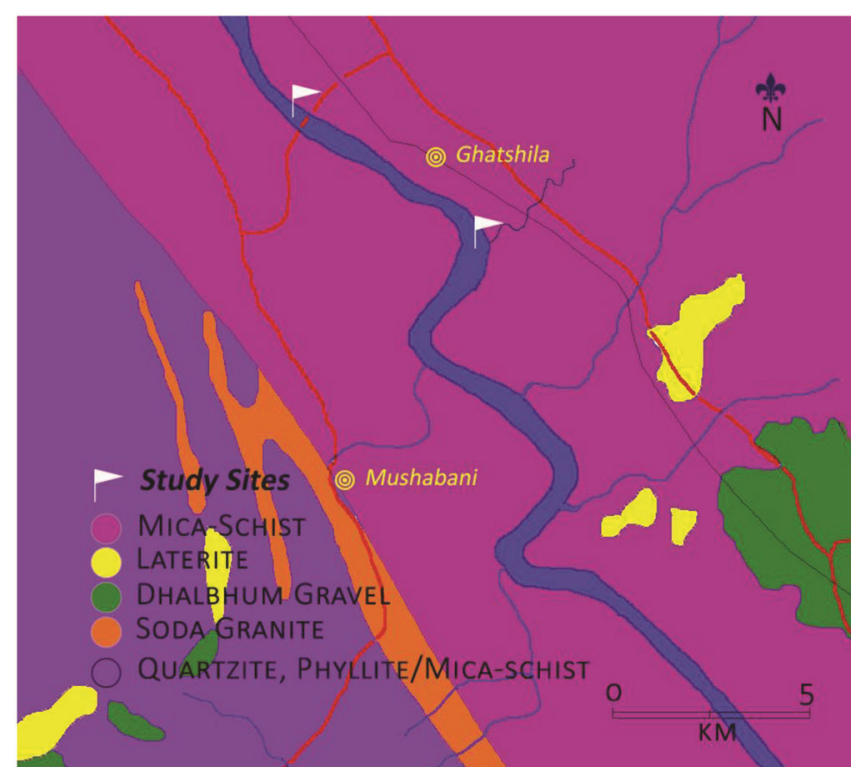

Figure 2. Geological setup of the study area ${ }^{22}$. 
Table 1. Result of $t$-test of values of $\gamma$ on different substrates

\begin{tabular}{|c|c|c|c|c|c|c|c|}
\hline \multirow[b]{2}{*}{ Item } & \multirow{2}{*}{$\begin{array}{c}\text { Null } \\
\text { hypothesis }\end{array}$} & \multirow{2}{*}{$\begin{array}{c}\text { Degree } \\
\text { of freedom }\end{array}$} & \multirow{2}{*}{$\begin{array}{l}\text { Calculated } \\
\text { value of } t\end{array}$} & \multicolumn{2}{|c|}{ Tabulated value of $t$} & \multicolumn{2}{|c|}{$\begin{array}{c}\text { Decision on } H_{0} \\
\text { at confidence level }\end{array}$} \\
\hline & & & & $t_{0.05}$ & $t_{0.01}$ & $95 \%$ & $99 \%$ \\
\hline Test of equality of $\gamma_{\mathrm{PM}}$ and $\gamma_{\mathrm{PM}}$ & $H_{0}: \gamma_{\mathrm{PD}}=\gamma_{\mathrm{PM}}$ & 62 & 7.79 & 1.670 & 2.388 & Rejected & Rejected \\
\hline Test of equality of $\gamma_{\mathrm{PM}}$ and $\gamma=2$ (ref. 18) & $H_{0}: \gamma_{\mathrm{PD}}=2$ & 33 & 0.47 & 1.692 & 2.445 & Accepted & Accepted \\
\hline Test of equality of $\gamma_{\mathrm{PM}}$ and $\gamma=2$ (ref. 18) & $H_{0}: \gamma_{\mathrm{PM}}=2$ & 29 & 27.42 & 1.699 & 2.462 & Rejected & Rejected \\
\hline
\end{tabular}

$\gamma_{\mathrm{PD}}=$ Average depth/radius ratio of potholes on quartzite: $\gamma_{\mathrm{PM}}=$ Average depth/radius ratio of potholes on mica-schist.

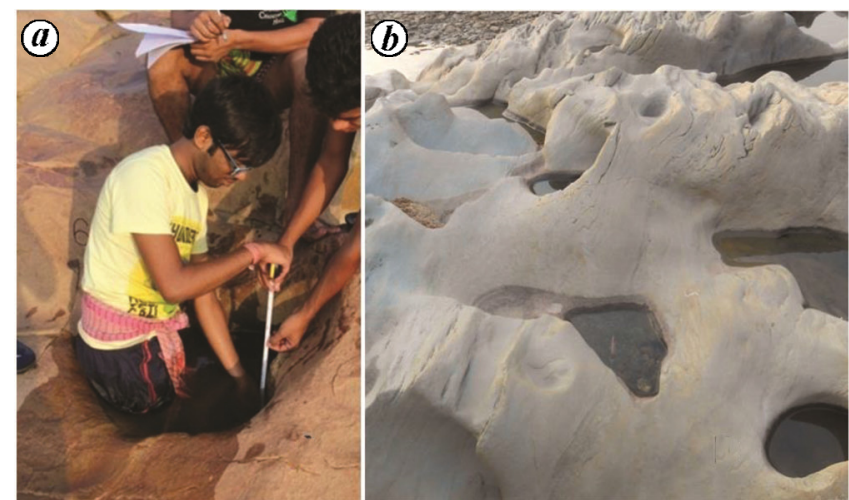

Figure 3. $\boldsymbol{a}$, The student within the pothole represents the scale and magnitude of depth and diameter of a pothole on quartzite substrate. $\boldsymbol{b}$, Potholes on mica-schist with higher variation in diameter of the aperture and lower value of $\gamma$.

following stages of a pothole evolution is greater than at its preceding stages. Once potholes grow to sufficient depths, however, increase in bed surface area and the associated increase in drag are believed to dissipate flow energy, thereby slowing the rate of pothole growth in a negative feedback ${ }^{31,32}$. It is found (Figure $5 a$ ) that when potholes of $\gamma<2$ are arranged in ascending order of $\gamma$, then with increasing $\gamma$, potholes radii show a (relatively) negative trend. However, negative change in radius is not possible; it is possible only for depth. In this phase $(\gamma<2)$, increase in radii is so slow compared to the rapid increase in depths, that it appears with a negative trend.

At the second phase $(\gamma>2)$, gap between the growth rate of depths and radii is decreased. Increase in radii also follows a trend of gentle but positive slope. With decreasing bottom shear stress ${ }^{18}$ at this phase, the rate of pothole deepening becomes slower but the hydraulic pound and abrasive action continue on walls resulting in an increase in radii (Figure $5 b$ ).

The average depth/radius ratio of 30 potholes on micaschist substrate $\left(\gamma_{\mathrm{PM}}\right)$ at Moubhandar is only 0.86 which indicates that the depth of potholes is much less than the diameter of apertures. $\gamma_{\mathrm{PM}}=0.86$ differs significantly from the findings of Pelletier et al. ${ }^{18}$ at both $95 \%$ and $99 \%$ confidence level. There are $16(53.33 \%)$ potholes in modal class (Figures $3 b$ and $4 b$ ) with a modal value of $\gamma_{\mathrm{PM}}=0.81$.


Figure 4. $\boldsymbol{a}$, Frequency distribution of $\gamma$ of potholes on quartzite substrate. The range of $\gamma$ is higher for potholes on this substrate. $\boldsymbol{b}$, Frequency distribution of $\gamma$ of potholes on mica-schist.

A relatively smaller value of $\gamma_{\mathrm{PM}}$ is explained as: (i) $\mathrm{Ji}$ et $a{ }^{25}$ found smaller depth/radius ratio in marine and hillside potholes because of less power of flowing water and smaller grinding stones. For flow in a relatively smooth channel, stream power was much less than that at Subarnarekha-Bhatajhor confluence. (ii) $\mathrm{N}$ component of linear law $d=0.673 r+4.976(N<1)$ and $r=0.94 d+$ $6.232(N<1)$, indicates faster rate of widening than deepening of potholes and smaller depth/radius ratio value. Inactive bed-load size larger grinding stones (pebble, cobble and boulder) in less stream power not only decelerate floor abrasion but also protect it from erosion by smaller suspended-load size tools ${ }^{25}$, reducing $\gamma_{\mathrm{PM}}$.

It is to be noted that $H_{0}: \gamma_{\mathrm{PM}}=2$ was also rejected at both $95 \%$ and $99 \%$ confidence level when 64 potholes 
RESEARCH COMMUNICATIONS

Table 2. Depth-radius linear and power law and correlation

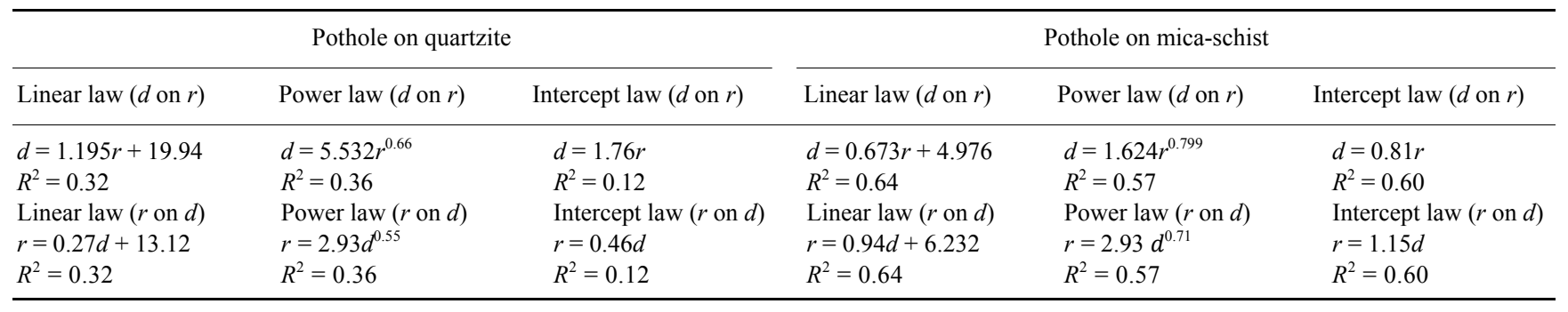


Figure 5. Potholes are arranged in ascending $\gamma$ and classified into two groups, $\gamma<2$ group and $\gamma>2$ group. In both the groups, increase in depth is faster than the radius. $\boldsymbol{a}$, Group having $\gamma<2$ shows a relatively negative trend in the change of radius with increasing $\gamma$. $b$, Group having $\gamma>2$ shows a positive but slow rate of increase in radius with increasing $\gamma$. Depth variation is shown by dashed lines and change in radius is shown by solid lines.

(34 on quartzite and 30 on mica-schist substrates) were considered together.

At a relatively lower vortex velocity, when larger grinding tools atop the floors remain in rest and protect them from further erosion, the hydraulic pound and abrasive action by relatively smaller particles continue to widen pothole walls (on a soft mica-schist substrate with low resistive power to erosive action) resulting in higher $r$ compared to $d$ and low value of $\gamma$.

Springer et $a l^{4,5}$ found power relation $\left(r=k d^{\varepsilon}\right.$ where $k$ and $\varepsilon$ are regression coefficients and $\varepsilon=0.57,0.67$ and 0.85 ) between average radius and depth of pothole. We found that $r=2.93 d^{0.55}$ on quartzite and $r=2.93 d^{0.71}$ on mica-schist, confirming earlier findings. Intercept of depth to radius $(d=1.76 r)$ for potholes on quartzite substrate corresponds to $d / r=\gamma=2$ (Figure $6 a$ ). But intercept of depth to average radius for potholes on micaschist substrate does not match the above equation ${ }^{18}$ and differ significantly $(d=0.81 r$; Figure $6 b)$.

Positive-tailed frequency distribution (mode $=1.85<$ median $=1.89<$ mean $=2.07)$ of $\gamma_{\mathrm{PD}}$ implies subsequent lessening in frequency by coalescence of potholes with their growth. Frequency distribution of $\gamma_{\mathrm{PM}}($ mean $=0.86$, median $=0.86$, mode $=0.81)$ also signifies the same but not so significantly.

Average variation in radius $\left(r_{\Delta}\right)$ of potholes on quartzite was $18.66 \%$. However, this variation on mica-schist was much higher (60.59\%). Faster and irregular widening of apertures and frequent coalescence of adjoining pothole give rise to higher degree of variation in radius $\left(r_{\Delta}\right)$ of potholes on the mica-schist substrate. Mica-schist is a relatively less resistant substrate compared to quartzite. As a result, hydraulic pound and abrasive action by smaller grinding tools on downstream wall made elongated potholes oriented towards flow direction.

Some bulbous potholes ${ }^{33}$ on quartzite substrate at Bhatajhor-Subarnarekha confluence have larger average chamber radius $\left(r_{\mathrm{c}}\right)$ than average aperture radius $(r)$ (Figure 7). There are 20 potholes with $\gamma<2$, out of which $20 \%$ of potholes have larger $r_{\mathrm{c}}$ than $r$ (Table 3 ). Out of 14 potholes with $\gamma>2,5(36 \%)$ have wider chamber with larger $r_{\mathrm{c}}$. Shear stress at the bottom of a pothole (which controls the rate of pothole growth) is maximized for potholes with $\gamma \sim 1$ and decreases nonlinearly with increasing $\gamma^{17}$. Shear stress variation with increasing $\gamma$ may be one of the reasons for potholes having $r_{\mathrm{c}}>r$. It was found that all the potholes having $r_{\mathrm{c}}>r$ had $\gamma>1$ (at which bottom shear stress is maximum) and no pothole with $\gamma<1$ had any wider chamber. Therefore, chambered potholes are totally absent on mica-schist.

Determination of critical size of mean radius, $M$ and critical depth $d_{c}$ for seminal potholes is important for (i) Depression with radius less than $M$ and depth less than $d_{c}$ cannot entrap and retain grinding stone to shape the germinal depression into a mature pothole ${ }^{25}$ and (ii) Depression with radius $>M$ and depth $>d_{\text {c }}$ can form stable and strong vortex and reach a maximum erosion 
Table 3. Fundamental statistics on potholes

\begin{tabular}{llll}
\hline Type of substrate & Average variation in radius $\left(r_{\Delta}\right)$ & Per cent of potholes having $r_{\mathrm{c}}>r$ & $r_{\mathrm{c}}$ in per cent of $r$ \\
\hline Quartzite & $18.66 \%$ & $20 \%$ of potholes with $\gamma \leq 2$ & $118.68 \%$ \\
Mica-schist & $60.59 \%$ & $36 \%$ of potholes with $\gamma \geq 2$ & $\mathrm{NA}$ \\
\hline
\end{tabular}
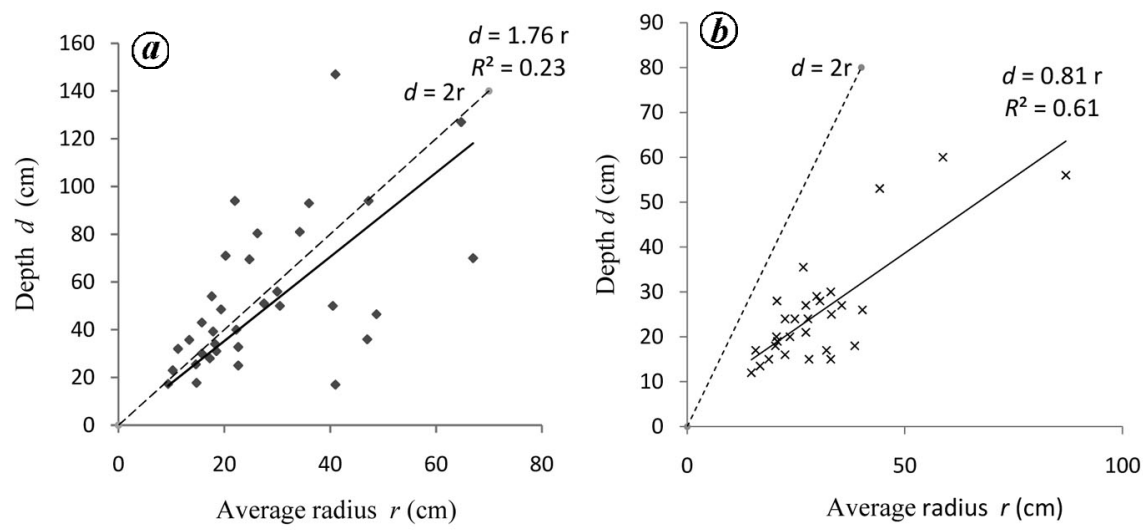

Figure 6. $\boldsymbol{a}$, Intercept of depth to average radius $(d=1.76 \times r)$ for potholes on quartzite substrate corresponds to $d / r=\gamma=2$ (by Pelletier et al. ${ }^{18}$ ). $\boldsymbol{b}$, Intercept of depth to average radius for potholes on mica-schist substrate does not correspond to $\gamma=d / r=2$ the above equation which is different $(d=0.81 \times r)$.

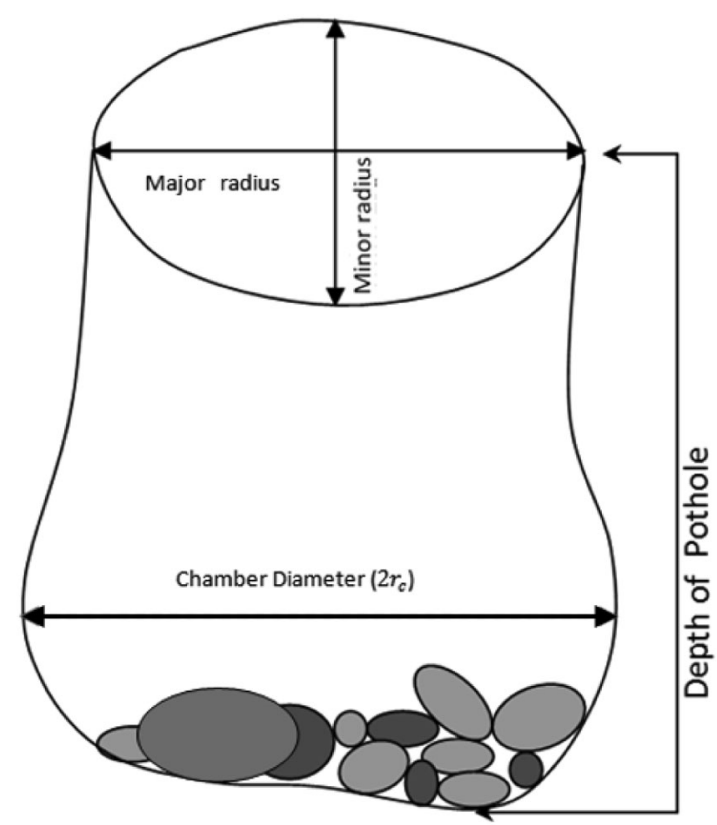

Figure 7. Definition of different parameters of a pothole.

potential of the fluids for efficient growth of pothole $\mathrm{e}^{34}$. We found that $M \sim 20 \mathrm{~cm}$ and $d_{\mathrm{c}} \sim 13 \mathrm{~cm}$ for potholes on quartzite and $M=5 \mathrm{~cm}$ and $d_{\mathrm{c}}=6 \mathrm{~cm}$ for potholes on mica-schist (Table 2).

Pelletier et al. ${ }^{18}$ found that the largest grinding tool $(G)$ episodically stored in the pothole was equal to the aver-


Figure 8. Relationship among $G, d$ and $r$.

age aperture radius $(r)$ of the pothole $(r \sim G)$. In the present study, we observed that $r=2.29 G: R^{2}=0.015$ or $G=0.44 r$ for potholes on quartzite (Figure 8). $G-r$ linear law, $r=1.222 G+13.45: R^{2}=0.101$ showed no significant relationship. The $G-d$ linear regression $d=4.151 G+5.434: R^{2}=0.263$ and $d=4.58 G$ affirms '... pothole depths increase in proportion to the diameter of the largest clasts episodically stored in potholes ${ }^{18}$.

Seven potholes constituting $23.33 \%$ of the sample size studied on mica-schist substrate at Moubhandar site were empty of grinding tools. Because of smaller $\gamma$, potholes could not retain grinding stones which were swept away by higher flow velocity during peak flow. $G-d$ linear law $d=0.552 x+22.43: R^{2}=0.032$ and $G-r$ linear law 


\section{RESEARCH COMMUNICATIONS}

$r=0.486 G+27.59: R^{2}=0.017$, represent no significant relation.

Lithology and geophysics of substrates significantly control potholes morphology. Morphometry of potholes on quartzite is significantly different from that on micaschist. Depth/radius ratio is higher for potholes on hard rocks (quartzite) than on soft rocks (mica-schist). The critical dimension of seminal depressions that gradually evolve into mature potholes is smaller on less resistant rocks like mica-schist than on more resistant rocks like quartzite. Variation of major and minor aperture radii of potholes on soft rock (mica-schist, $60.59 \%$ ) is 3.25 times higher than that on hard rock (quartzite, 18.66\%). Potholes of $d / r>2$ may evolve to bulbous shape with $r_{\mathrm{c}}>r$. The $d-G$ and $r-G$ linear relations found in potholes on softer substrate (mica-schist) are insignificant which are significant for potholes on harder rocks (quartzite).

1. Hancock, G. S., Anderson, R. S. and Whipple, K. X., Beyond power: bedrock river process and form. In Rivers Over Rock: Fluvial Processes in Bedrock Channels (eds Tinkler, K. J. and Wohl, E. E.), American Geophysical Union Monograph, American Geophysical Union, Washington DC, USA, 1998, vol. 107, pp. 35-60.

2. Whipple, K. X., Hancock, G. S. and Anderson, R. S., River incision into bedrock: mechanics and relative efficacy of plucking, abrasion and cavitation. Geol. Soc. Am. Bull., 2000, 112, 490-503.

3. Whipple, K. X., Snyder, N. P. and Dollenmayer, K., Rates and processes of bedrock incision by the Upper Ukak River since the 1912 Novarupta ash flow in the Valley of Ten Thousand Smokes, Alaska. Geology, 2000, 28, 835-838.

4. Springer, G. S., Tooth, S. and Wohl, E. E., Dynamics of pothole growth as defined by field data and geometrical description. J. Geophys. Res., 2005, 110, F04010.

5. Springer, G. S., Tooth, S. and Wohl, E. E., Theoretical modeling of stream potholes based upon empirical observations from the Orange River, Republic of South Africa. Geomorphology, 2006, 82, 160-176.

6. Elston, E. D., Potholes: their variety, origin and significance (I), Sci. Mon., 1917, 5, 554-567.

7. Elston, E. D., Potholes: their variety, origin and significance (II). Sci. Month., 1918, 6, 37-53.

8. Alexander, H. S., Pothole erosion. J. Geol., 1932, 40, 305-337; doi:10.1086/623954.

9. Kunert, M. and Coniglio, M., Origin of vertical shafts in bedrock along the Eramosa River Valley near Guelph, Southern Ontario. Can. J. Earth Sci., 2002, 39, 43-52.

10. Morgan, A. V., Late Weichselian potholes near Wolverhampton, England. J. Glaciol., 1970, 9, 125-133.

11. Allen, J. R. L., Sedimentary structures: their character and physical basis, Vol. 2. In Developments in Sedimentology, Elsevier, Amsterdam, 1982, 30B, pp. 663.

12. Jennings, J. N., Swirlholes and related bedrock River channel forms. Aust. Geogr., 1983, 15, 411-414.

13. Wohl, E. E. and Ikeda, H., Experimental simulation of channel incision into a Coqhesive substrate at varying gradients. Geology, 1997, 25, 295-298.

14. Gjessing, J., Potholes in connection with plastic scouring forms. Geogr. Ann. A, 1967, 49, 178-187.

15. Kor, P. S. G. and Cowell, D. W., Evidence for catastrophic subglacial meltwater sheetflood events on the Bruce Peninsula, Ontario. Can. J. Earth Sci., 1998, 35, 1180-1202.
16. Lugt, H. J., Vortex Flow in Nature and Technology, Wiley and Sons, New York, 1983, p. 297.

17. Diffendal, J. F., Gully, scour hole and pothole development at the base of the Gering Formation (Miocene?), Southeastern Banner County, Nebraska. Contrib. Geol., 1982, 21, 1-6.

18. Pelletier, J. D., Sweeney, K. E., Roering, J. J. and Finnegan, N. J., Controls on the geometry of potholes in bedrock channels. Geophys. Res. Lett., 2015, 42(3), 797-803; doi:10.1002/ 2014GL062900.

19. Abbott, A. T. and Pottratz, S. W., Marine pothole erosion, Oahu, Hawaii. Pac. Sci., 1969, 23, 276-290.

20. Sengupta, S. and Kale, V. S., Evaluation of the role of rock properties in the development of potholes: a case study of the Indrayani knickpoint, Maharashtra. J. Earth Syst. Sci., 2011, 120(1), 2011, pp. 157-165.

21. Galudih Barrage, Salient Features of Galudih Barrage, Govt. of Jharkhand, India, 1970.

22. GSI, District Resource Map, East Singhbhum, Jharkhand, Geological Survey of India, Kolkata, Govt. of India, 2006.

23. Richardson, K. and Carling, P. A., A Typology of Sculpted Forms in Open Bedrock Channels, The Geological Society of America, Colorado, USA, 2005, vol. 392, ISBN: 0-8137-2392-2.

24. Das, N. G., Statistical Methods, Part-II, M. Das \& Co, Calcutta, 2007, pp. 256, 259.

25. Ji, S., Li, L. and Zeng, W., The relationship between diameter and depth of potholes eroded by running water. J. Rock Mech. Geotech. Eng., 2018, 10, 818e831.

26. Álvarez-Vázquez, M. Á., de Uña-Álvarez, E., Growth of sculpted forms in bedrock channels, (Miño River, northwest Spain). Curr. Sci., 2017, 112(5), 996-1002.

27. Kale, V. S. and Shingade, B. S., A morphological study of potholes of Indrayani knick point (Maharashtra). In Explorations in the Tropics (eds Datye, V. S. et al.), Dr Dikshit Felicitation Volume, Pune, 1987, pp. 206-214.

28. Sato, S., Matsuura, H. and Miyazaki, M., Potholes in Shikoku, Japan, Part 1. Potholes and their hydrodynamics in Kurakawa River, Ehime. Memoirs of the Faculty of Education, Ehime University Ser. III, Natural Science, 1987, 7, 127e90.

29. Ren, H. Q., Yuan, X. Z., Liu, H., Yue, J. S., Wang, X. F., Liu, S. S. and Qi, J., Shape and benthic invertebrate community features of the potholes in Wubu River, Chongqing. Chin. J. Ecol., 2015, 34, $3402 \mathrm{e} 8$.

30. Das, B. C., Development of streambed potholes and the role of grinding stones. J. Environ. Geogra., 2018, 11(1-2), 9-16.

31. Johnson, J. P. and Whipple, K. X., Feedbacks between erosion and sediment transport in experimental bedrock channels. Earth Surf. Proc. Landf., 2007, 32, 1048-1062.

32. Johnson, J. P. L., Whipple, K. X. and Sklar, L. S., Contrasting bedrock incision rates from snowmelt and flash floods in the Henry Mountains, Utah. Geol. Soc. Am. Bull., 2007, 122, 1600-1615.

33. Lorenc, M. W., Barco, P. M. and Saavedra, J., The evolution of potholes in granite bedrock, W Spain. Catena, 1994, 22, 265-274.

34. Springer, G. S. and Wohl, E. E., Empirical and theoretical investigations of sculpted forms in Buckeye Creek Cave, West Virginia. J. Geol., 2002, 110(4), 469-481.

ACKNOWLEDGEMENTS. I thank my students of M Sc 3rd Semester with special paper Fluvial Geomorphology (session 2014-16) for data collection on potholes.

Received 4 February 2018; revised accepted 12 March 2019

doi: $10.18520 / \mathrm{cs} / \mathrm{v} 117 / \mathrm{i} 2 / 275-281$ 